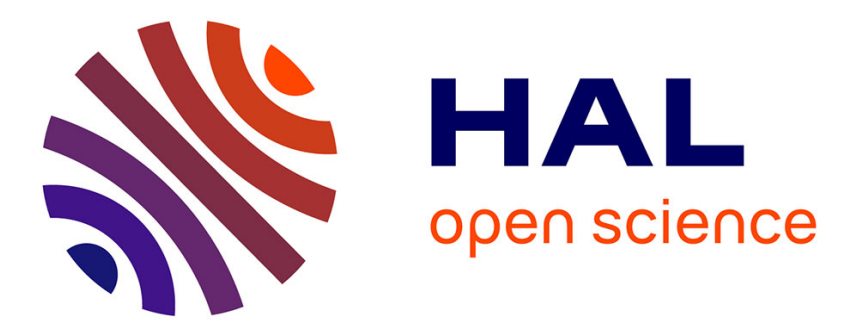

\title{
A comparison of vibrating beam resonators in Quartz, GaPO(4), LGS and LGT
}

\author{
G. Douchet, F. Sthal, E. Bigler, R. Bourquin
}

\section{To cite this version:}

G. Douchet, F. Sthal, E. Bigler, R. Bourquin. A comparison of vibrating beam resonators in Quartz, GaPO(4), LGS and LGT. Solid State Sciences, 2010, 12 (3), pp.325-332. 10.1016/j.solidstatesciences.2009.08.005 . hal-00609381

\section{HAL Id: hal-00609381 https://hal.science/hal-00609381}

Submitted on 22 Apr 2021

HAL is a multi-disciplinary open access archive for the deposit and dissemination of scientific research documents, whether they are published or not. The documents may come from teaching and research institutions in France or abroad, or from public or private research centers.
L'archive ouverte pluridisciplinaire HAL, est destinée au dépôt et à la diffusion de documents scientifiques de niveau recherche, publiés ou non, émanant des établissements d'enseignement et de recherche français ou étrangers, des laboratoires publics ou privés. 


\title{
A comparison of vibrating beam resonators in Quartz, $\mathrm{GaPO}_{4}$, LGS and LGT
}

\author{
G. Douchet, F. Sthal, E. Bigler*, R. Bourquin \\ Institut FEMTO-ST, CNRS UMR 6174, Frequency and Time Department, 26, Chemin de l'Epitaphe, Besançon Cedex 25030, France
}

\begin{abstract}
The present paper reviews and compares the properties of vibrating beam resonators in length-extensional, flexural and cylindrical-torsional modes; resonators are designed and built with new piezoelectric materials: Gallium orthophosphate $\left(\mathrm{GaPO}_{4}\right)$, Langasite (LGS) and Langatate (LGT). Their characteristics are compared with the results obtained with the same structures built in classical Quartz crystal.

For all 3 new crystals, temperature-compensated cuts have been found for length-extensional and flexural modes by a theoretical analysis. Experiments have been made on test beams fabricated by conventional precision lapping/machining and photolithography to deposit electrodes. The existence of temperature-compensated cuts for length-extensional resonators is experimentally confirmed.

The possibilities of using temperature-compensated cylindrical resonators in the torsional modes are analysed and their temperature sensitivity is computed.
\end{abstract}

\section{Introduction}

Since the last 20 years, new piezoelectric materials have been developed, among them, Gallium orthophosphate $\left(\mathrm{GaPO}_{4}\right)[1]$ and the Langasite family (Lanthanum Gallium Silicate $\mathrm{La}_{2} \mathrm{Ga}_{5} \mathrm{SiO}_{14} \mathrm{LGS}$ [2], Lanthanum gallium tantalate, $\mathrm{La}_{3} \mathrm{Ga}_{5.5} \mathrm{Ta}_{0.5} \mathrm{O}_{14}$ LGT [3]) have been studied in detail for high-performance piezoelectric resonator applications. The reasons of this interest are

- the material is now available commercially in crystal sizes compatible with production machines used in the industry;

- $\mathrm{GaPO}_{4}$, LGS and LGT can be used at high temperatures without loosing their piezoelectric properties;

- $\mathrm{GaPO}_{4}$, LGS and LGT exhibit temperature-compensated cuts for various modes of vibration: bulk waves, surface waves, vibrating beams and cylinders.

What is the interest of piezoelectric beam resonators? Historically, beam resonators were developed in the years 1930-1940 as the standard piezoelectric element to stabilize the frequency of high-

\footnotetext{
* Corresponding author. Tel.: +33 3814028 32; fax: +33 381883528 E-mail address: bigler@ens2m.fr (E. Bigler).
}

performance oscillators. This kind of resonators was superseded by thickness-shear resonators in the field of precision time and frequency control, however vibrating Quartz beams in flexural modes are the key elements of very successful miniature wrist-watch oscillators [4], a device built by hundreds of millions each year.

This kind of resonators is also used in atomic force microscope as a shear-force sensor [5]. Several other sensor applications built from Quartz crystals, like viscosimeters based on cylindrical resonators in torsional modes could also be foreseen with the new crystals in vibrating modes at high temperatures [6].

In this paper, the properties of vibrating-beam resonators made in $\mathrm{GaPO}_{4}$, LGS and LGT are investigated. The temperature-induced frequency shifts are computed and temperature-compensated orientations of the crystal are found for which the first-order temperature coefficient of the resonant frequency (TCF) is zero.

Taking into account that no resonator or sensor applications can be developed for Quartz at high temperatures (due to the $\alpha-\beta$ phase transition at $573{ }^{\circ} \mathrm{C}$ ), the possibility to use new piezoelectric materials at high temperatures is investigated.

Another rationale is to investigate temperature effects in resonators built with the new piezoelectric materials. For Quartz, material constants and their temperature derivates are well known; however for new materials, only a limited number of vibrating modes have been investigated and tested for 


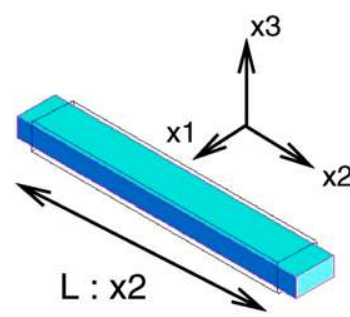

length extensional

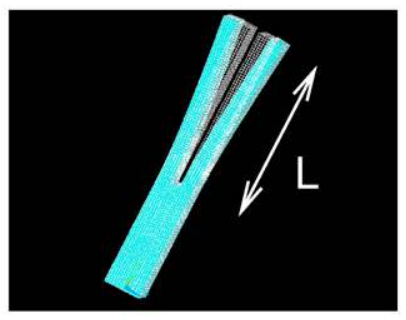

flexural, tuning fork

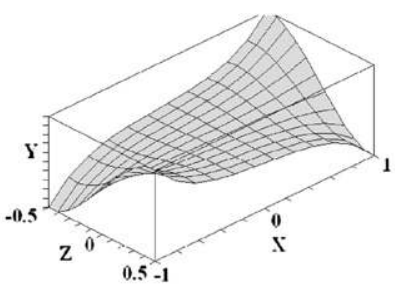

torsional / cylinder

$L: x 2$

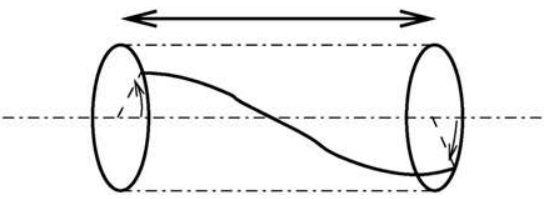

Fig. 1. Different vibrating modes of beam resonators.

frequency-temperature effects, mostly thickness-shear. There is a need for more experimental data to improve the knowledge of temperature derivatives of elastic constants: experiments with beam resonators will allow to expand the database of modes for a precise determination of temperature effects.

\section{Quartz, $\mathrm{GaPO}_{4}, \mathrm{LGS}$ and LGT beam resonators}

Three different kinds of beam resonators have been investigated (Fig. 1):

- length-extensional resonators,

- flexural and tuning-fork resonators,

- torsional modes of cylinders.
Neglecting the influence of piezoelectricity on the resonant frequency, simple analytical models [7,8], yield the lowest-order resonant frequency $f_{1}$ of the structures:

- for length-extensional modes of a free-free beam:

$$
f_{1}=\frac{1}{2 L} \sqrt{\frac{1}{\rho S_{22}}}
$$

- for flexural modes of a clamped-free beam:

$f_{1}=\frac{3.42}{2 \pi L^{2}} \sqrt{\frac{\mathbf{I}}{\rho w t S_{22}}}$
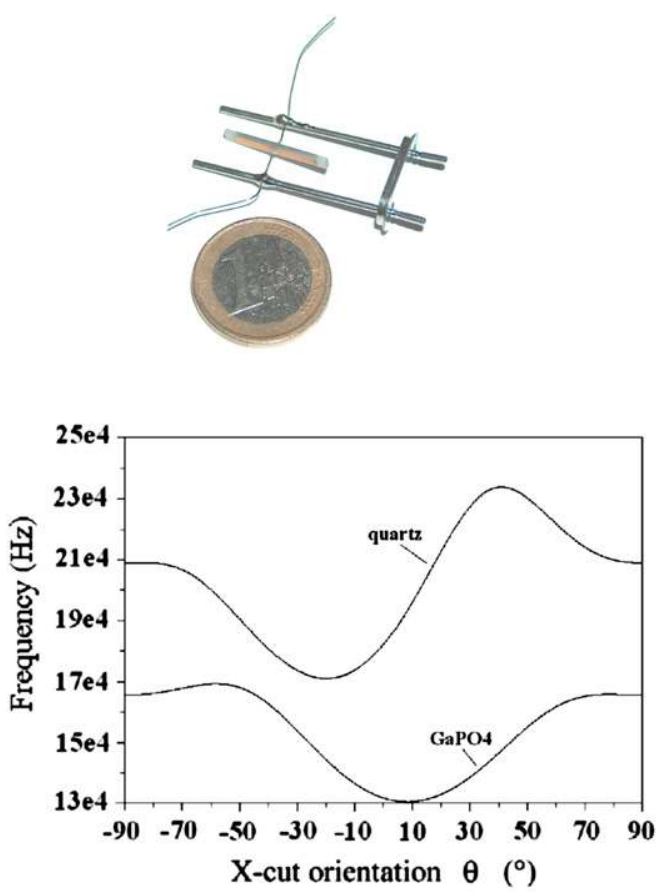

Frequency vs. cut angle
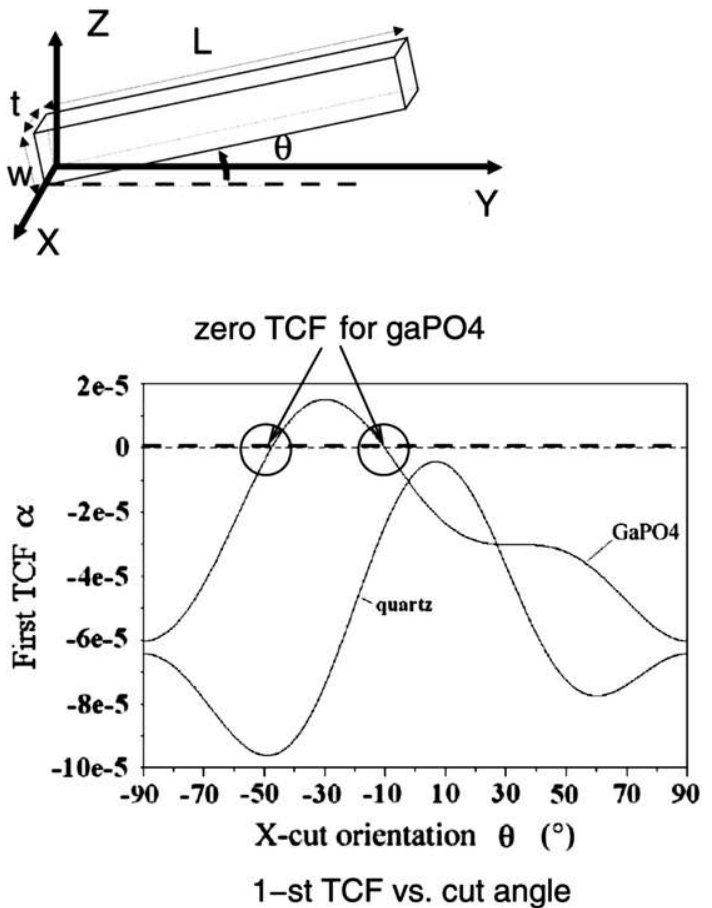

Fig. 2. Temperature-compensated cuts in Quartz and $\mathrm{GaPO}_{4}$, vibrating beams in length-extensional mode. 


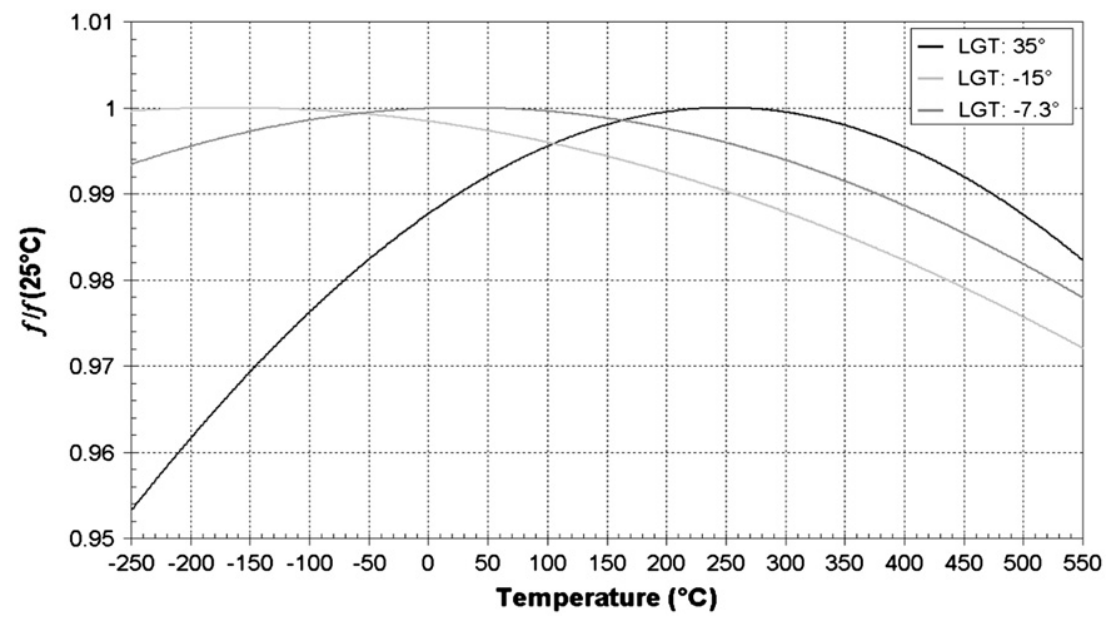

Fig. 3. LGT, length-extensional: predictions of frequency vs. temperature for cut angle theta $=-7.3,-15$ and $+35^{\circ}$.

- for torsional modes of a free-free cylinder:

$f_{1}=\frac{1}{4 L} \sqrt{\frac{2 C_{66} C_{44}}{\rho\left(C_{66}+C_{44}\right)}}$

Where:

- $f_{1}$ is the resonant frequency of the lowest-order mode;

- $L$ is the beam length, $w$ is the beam width and $t$ the beam thickness;

- $\mathbf{I}$ is the inertia of the beam, $\mathbf{I}=\frac{w t^{3}}{12}$

- $\rho$ is the mass density of the crystal, $S_{\mathrm{ij}}$ are the compliance elastic constants and $C_{\mathrm{ij}}$ stiffness constants.

\section{Modelling temperature-compensated cuts}

One of the most important properties of piezoelectric resonators built in Quartz, $\mathrm{GaPO}_{4}$, LGT and LGS is their ability to allow the design of temperature-insensitive vibrating devices, taking advantage of anisotropy of the crystals and the specific behaviour of temperature dependence of material constants to cancel the firstorder temperature derivatives of the resonant frequency. In order to investigate for temperature-compensated modes, the following approach has been implemented [7,9]:

- change length $L$ and lateral dimension $t$ according to anisotropic thermal expansion ( $f_{1}$ is actually independent from width $w$ );

- change specific mass $\rho$ according to thermal expansion;

- change elastic stiffness constants $C_{\mathrm{ij}}$ and compliance $S_{\mathrm{ij}}$ according to their $1 \mathrm{st}$ and 2 nd order temperature coefficients;

- re-compute frequency for each temperature and fit the dependence to a 2nd order polynomial;

- find 1st order and 2nd order temperature coefficients of frequency (TCF);

- look for cut angles for which the 1st order TCF is zero.

The data for mass density, coefficients of thermal expansion, temperature derivatives of elastic constants are taken from Refs. [10-12]. Cut angles for quartz are taken orientated according to Ref. [13]; for new crystals, the new IEEEE standard is used [14].

It has been found that for all crystals: Quartz, $\mathrm{GaPO}_{4}$, LGT and LGS, temperature-compensated orientations exist for beam resonators. Theoretical and experimental results are now presented for all crystals.

\section{Temperature-compensated cuts: length-extensional}

For length-extensional resonators, it is a classical result that Quartz does not exhibit a perfectly temperature compensated orientation for singly-rotated cuts (IEEE angle $\varphi=0$ [14]). Fig. 2 shows that for new crystals, however, several temperaturecompensated orientations exist for which the turnover point is at room temperature in the case of length-extensional resonators.

For LGT, the model predicts a temperature-compensated singlyrotated cut at $250^{\circ} \mathrm{C}$ for $\theta=-15^{\circ}$ (Fig. 3). By varying the cut angle, different operating temperatures with a zero TCF can be selected for each application (Fig. 4).

A comparison between theoretical predictions at room temperature and experiments for LGT is presented in Fig. 5. The model and experiments agree well but not perfectly. The reasons for this are very probably:

- the fact that temperature coefficients of elastic constants have been extracted from thickness-shear resonator measurements only;

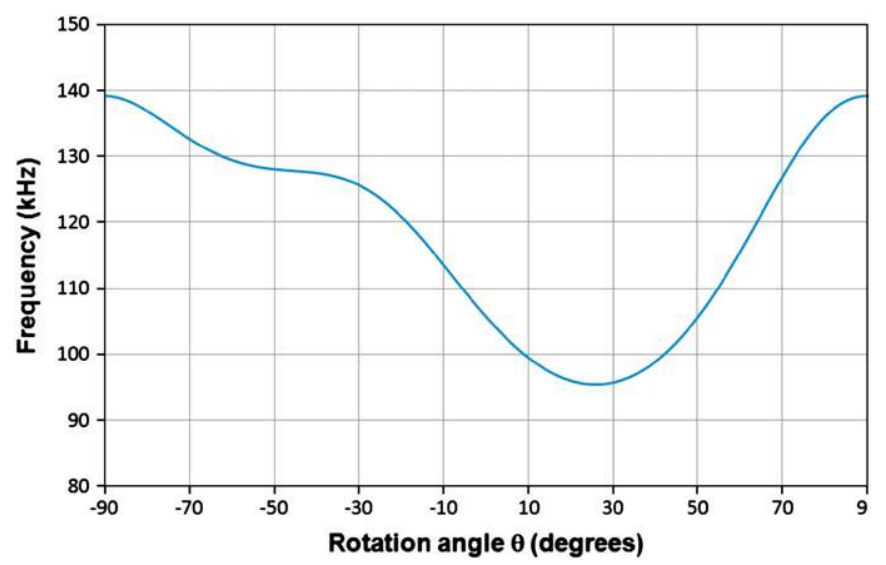

Fig. 4. LGT, predictions for the lowest resonant frequency of a $20 \mathrm{~mm}$ long lengthextensional resonator. 


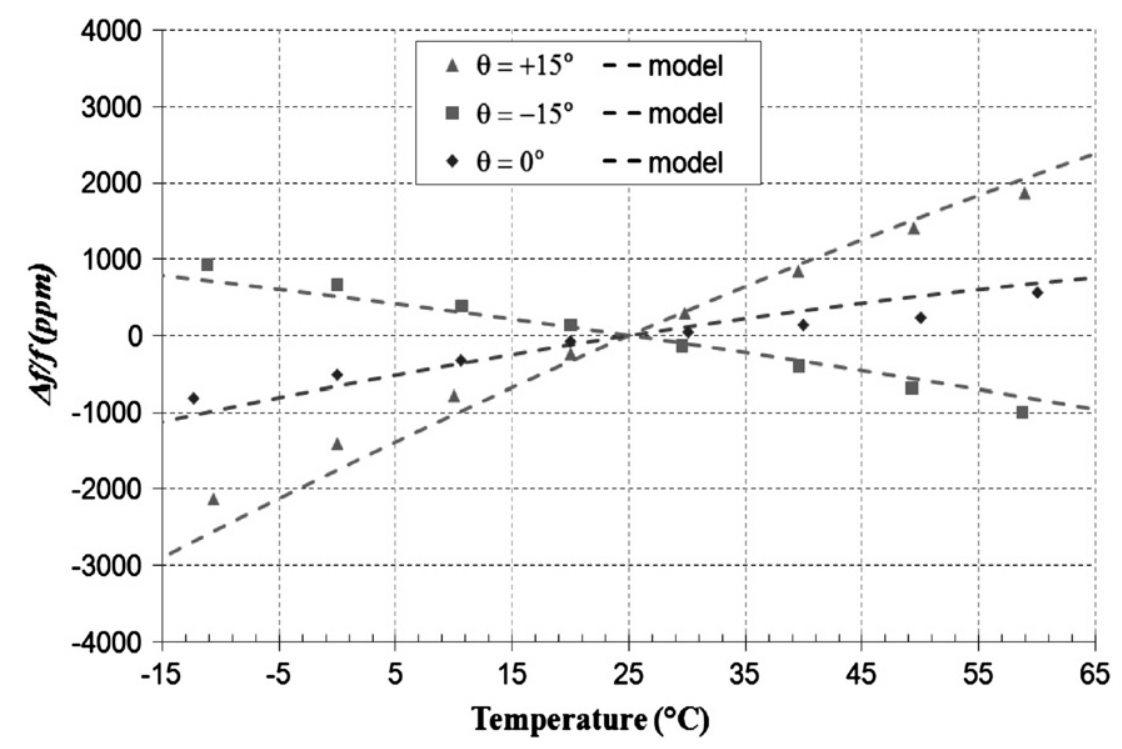

Fig. 5. LGT, length-extensional: frequency vs. temperature experiments for cut angle theta $=-15,0$ and $+15^{\circ}$.

- the present model does not take into account piezoelectric effects and could be improved by using a better definition of temperature derivatives of fundamental elastic constants [15].

The Table 1 presents the different values of the frequency constant (in $\mathrm{Hz} \mathrm{mm}$ ) and the second order coefficients for temperature-compensated length-extensional modes. For quartz, no temperature-compensated mode exists among singly-rotated cuts. The values for the BT-cut of quartz and AT-cut of $\mathrm{GaPO}_{4}$ are given only for comparison of the magnitude.

The (Table 2) presents the experimental motional parameters actually measured on different length-extensional resonators made in LGS and LGT in order to experimentally determine the optimum temperature-compensated cut. All resonators are $20 \mathrm{~mm}$ long, cross-section of the beam: $2 \mathrm{~mm} \times 1 \mathrm{~mm}$. All parameters were measured at room temperature under atmospheric pressure.

\section{Temperature-compensated cuts: flexural}

A similar approach is applied to flexural resonators. Note the absolute similarities with the length-extensional of the curves giving the 1 st TCF vs. the cut angle $\theta$. This behavior is very similar to what was known for quartz (Fig. 6).

For $\mathrm{GaPO}_{4}$, a temperature-compensated cut is predicted at $400{ }^{\circ} \mathrm{C}$ for a cut angle $\theta=-18.2^{\circ}$ (Fig. 7).

Two temperature-compensated cuts are predicted for LGS at room temperature (Fig. 8).

The following table (Table 3 ) presents the different values of second order coefficients for temperature-compensated flexural modes. For quartz, no temperature-compensated flexural mode exists.

Experimental verifications are now under test for LGS with devices fabricated by photolithography, gold thin-film deposition and precision diamond saw machining (Fig. 9).

\section{Temperature-compensated cuts: torsional (cylinder)}

Temperature effects for the 1st torsional mode of a cylinder are computed according to equation (3). All crystals are expected to have temperature-compensated cuts for singly-rotated cuts and the results are summarised in Table 4.

Table 1

Frequency constant and second-order temperature coefficient of frequency for rectangular beams vibrating in length-extensional mode.

\begin{tabular}{|c|c|c|c|c|c|c|c|c|c|}
\hline & Quartz & $\mathrm{GaPO}_{4}$ & $\mathrm{GaPO}_{4}$ & $\mathrm{GaPO}_{4}$ & LGS & LGS & LGS & LGT & LGT \\
\hline Extension & $\mathrm{BT}-49^{\circ}$ & $\mathrm{AT}-15^{\circ}$ & $\mathrm{LE}-8^{\circ}$ & $\mathrm{LE}-52.6^{\circ}$ & Y cut & $\mathrm{LE}-7^{\circ}$ & LE $62^{\circ}$ & $\mathrm{LE}-7.3^{\circ}$ & LE $68.6^{\circ}$ \\
\hline $\begin{array}{l}\text { Frequency } \\
\text { constant } \\
(\mathrm{MHz} \mathrm{mm})\end{array}$ & 2.85 & 2.1 & 2.0 & 2.55 & 2.2 & 2.2 & 2.7 & 2.2 & 2.5 \\
\hline$\left|T_{f}^{(2)}\right|\left(10^{-9} /{ }^{\circ} \mathrm{C}^{2}\right)$ & 40 & 20 & 7.5 & 1.4 & 50 & 53 & 129 & 83 & 102 \\
\hline
\end{tabular}

Table 2

Motional parameters of rectangular beam resonators vibrating in length-extensional mode.

\begin{tabular}{|c|c|c|c|c|c|c|}
\hline Extension & $\operatorname{LGS} \theta=-25^{\circ}$ & $\operatorname{LGS} \theta=0^{\circ}$ & $\operatorname{LGS} \theta=25^{\circ}$ & LGT $\theta=-25^{\circ}$ & LGT $\theta=0^{\circ}$ & LGT $\theta=25^{\circ}$ \\
\hline Freq. (kHz) & 111.427 & 130.144 & 100.691 & 117.695 & 105.895 & 97.627 \\
\hline$R(\Omega)$ & 2112 & 550 & 1300 & 1300 & 5449 & 2090 \\
\hline$L(\mathrm{H})$ & 39 & 16 & 16 & 17.7 & 14.5 & 17.6 \\
\hline$C(\mathrm{pF})$ & 38 & 127 & 152 & 103 & 155 & 150 \\
\hline$C_{0}(\mathrm{pF})$ & 1 & 68 & 9 & 5 & 6 & 5 \\
\hline$Q$ (in air) & 18200 & 20500 & 18900 & 9412 & 1773 & 5423 \\
\hline
\end{tabular}



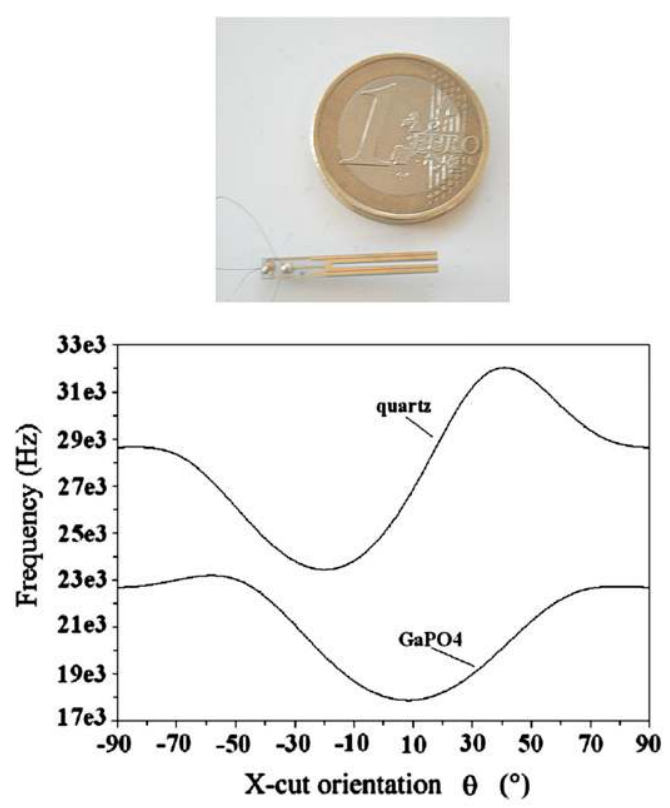

Frequency vs. cut angle
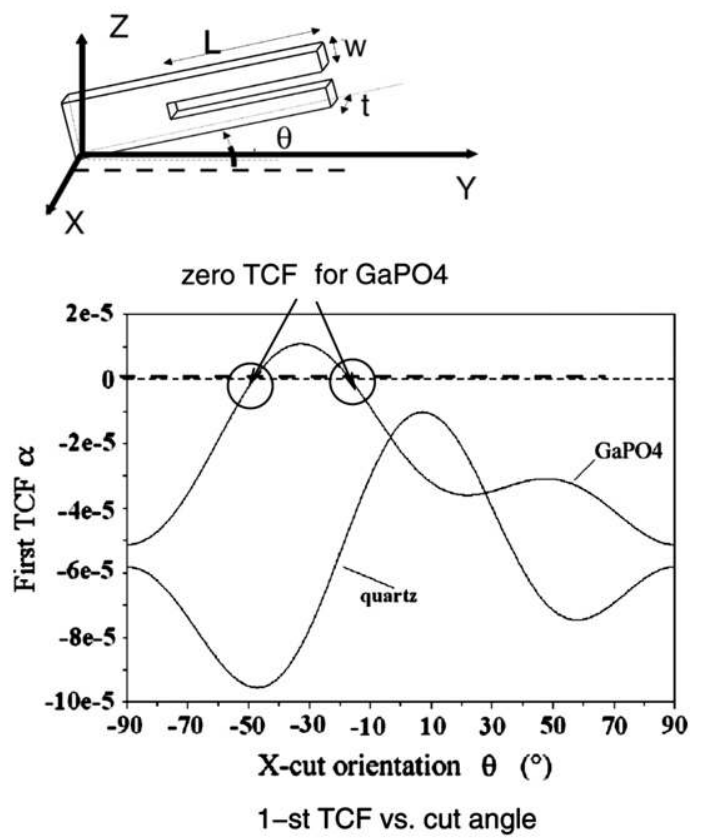

Fig. 6. Quartz and $\mathrm{GaPO}_{4}$, predicted temperature-compensated cuts for flexural resonators.

\section{Discussion and conclusion}

\subsection{Summary of results already obtained}

A comparison of new crystals with Quartz for applications to beam resonators can be summarised as follows:

- Resonant frequencies are found smaller with $\mathrm{GaPO}_{4}$, LGS and LGT, this is no surprise taking into account the higher mass density. A possible advantage is that for the same frequency, devices can be made smaller (Fig. 10).
- All 3 kinds of modes: extensional, flexural and torsional/ cylinder exhibit temperature-compensated orientations at room temperature for singly-rotated cuts. Temperaturecompensated cuts are predicted at high temperatures, but a good reliable set of high-temperature constants is required for LGS and LGT in order to predict the actual orientations precisely.

- Torsional modes of cylinders are already applied to viscosimeters in Quartz, potential applications exist at high temperatures with other crystals.
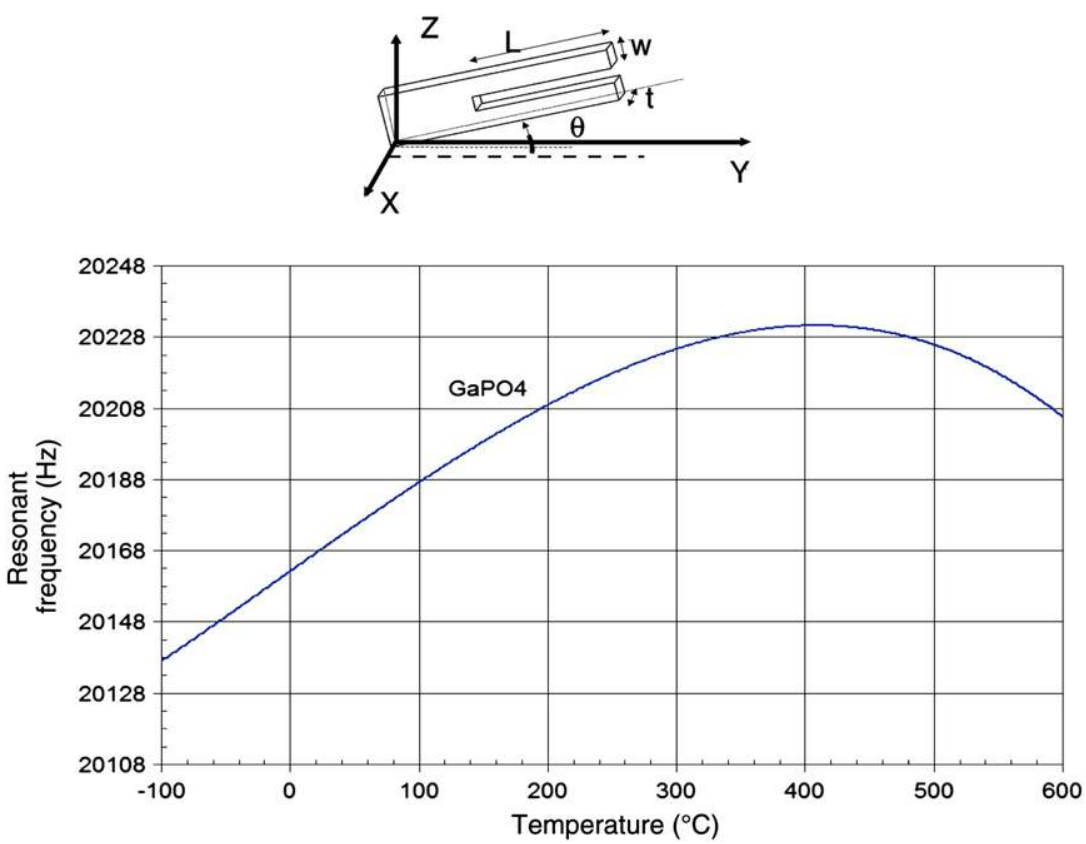

Fig. 7. Flexural/tuning fork: a temperature-compensated cut for $\mathrm{GaPO}_{4}$ at high temperature, for a cut angle $\theta=-18.2^{\circ}$. 

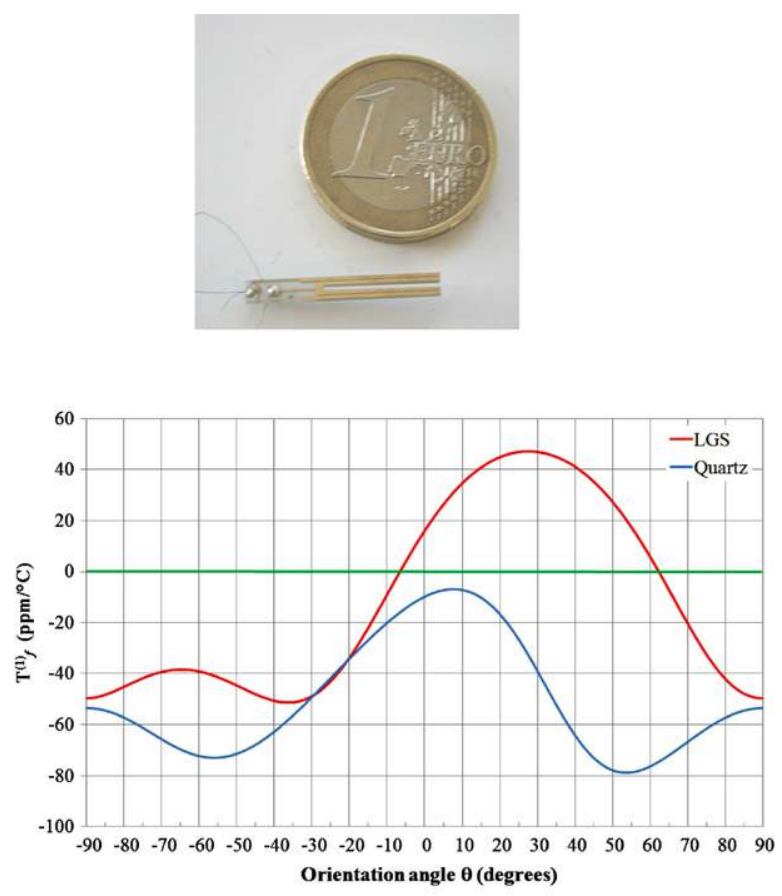

1-st TCF vs. cut angle
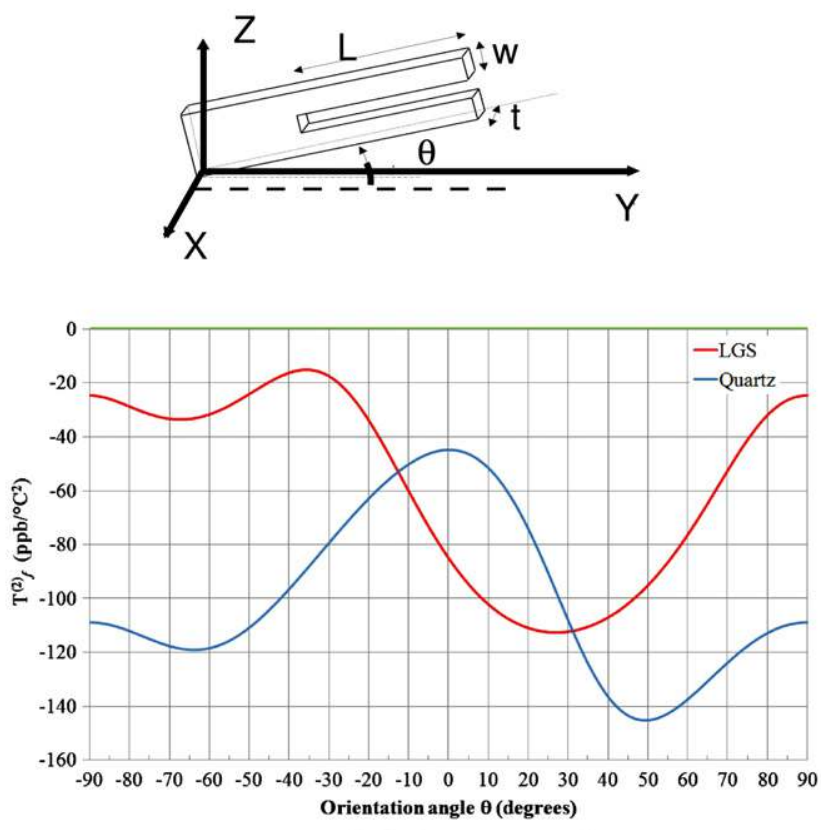

2-nd TCF vs. cut angle

Fig. 8. Quartz and LGS, predicted temperature coefficients for flexural resonators.

Table 3

Second-order temperature coefficient of frequency for rectangular beams vibrating in flexural mode.

\begin{tabular}{lccclll}
\hline & $\mathrm{GaPO}_{4}$ & $\mathrm{GaPO}_{4}$ & LGS & LGS & LGT & LGT \\
\hline Flexion & $-14.1^{\circ}$ & $-53.7^{\circ}$ & $-4^{\circ}$ & $60.3^{\circ}$ & $-6.6^{\circ}$ & $69^{\circ}$ \\
$\left|T_{f}^{(2)}\right|\left(10^{-9} /{ }^{\circ} \mathrm{C}^{2}\right)$ & 8.5 & 2.8 & 57 & 127 & 87 & 99 \\
\hline
\end{tabular}

It appears that the lowest overall temperature sensitivity for all crystals listed in this paper in $\mathrm{GaPO}_{4}$ for which the second-order temperature coefficients are smaller than quartz and for some orientations, one order of magnitude is lower for LGS and LGT.

However, the resonant frequencies are lower in $\mathrm{GaPO}_{4}$ and LGS/ LGT than in quartz, as summarised in Table 5:

\subsection{Strong points and weak points of new piezoelectric crystals for beam resonator applications}

1. Quartz has been extensively studied for one century, reliable industrial sources of quartz crystal exist.

2. Quartz cuts close to the Z-cut can be batch processed by chemical etching.

3. Temperature-compensated cuts exist for flexural and torsional quartz beam resonators.

Table 4

Temperature-compensated cuts $(1 \mathrm{st} \mathrm{TCF}=0)$ for torsional cylinder modes.

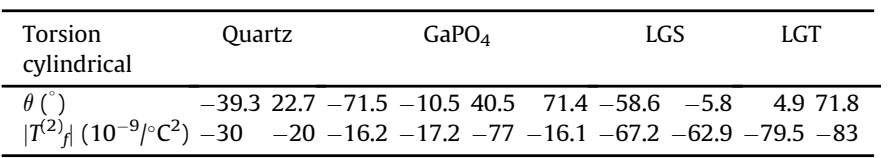

The success of quartz for tuning-fork resonators can be explained as follows:

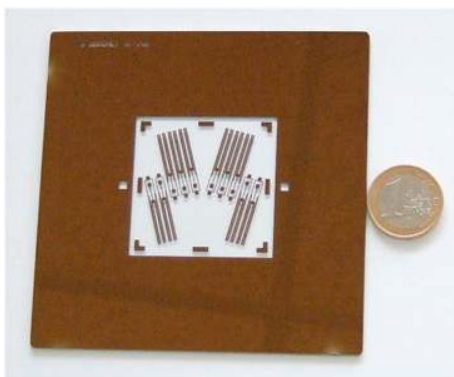

Mask pattern for electrode deposition

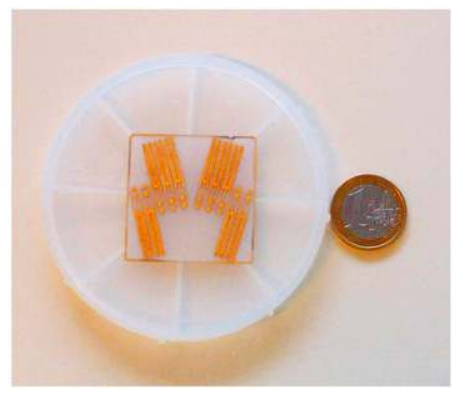

Patterned LGS blank before machining by precision diamond saw blade

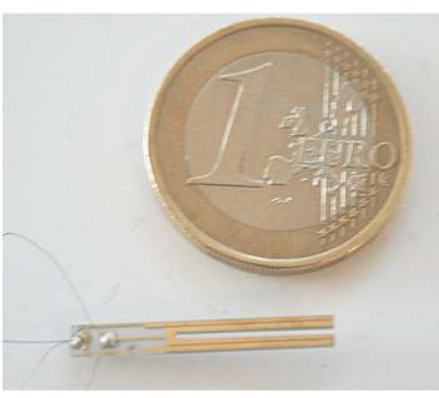

final device

Fig. 9. Fabrication of test devices by photolithography, gold thin-film deposition and precision diamond saw machining. 

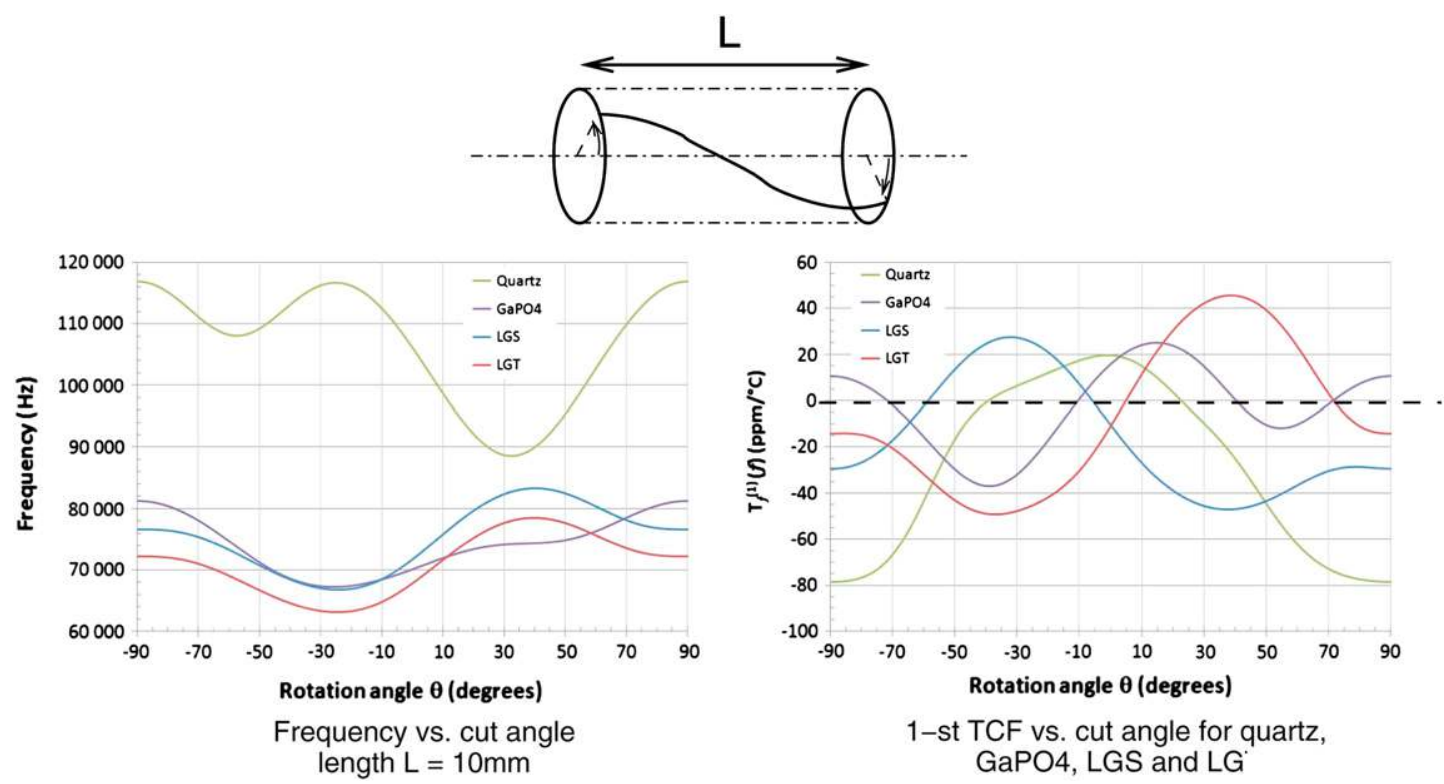

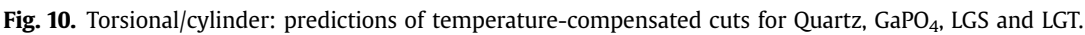

The weak points of new piezoelectric crystals, to date, are:

1. So far, the industrial research and development of new piezoelectric crystals is far from the present state of industrial development for quartz. For the LGS/LGT family, only a few suppliers exist, most commercially available crystals actually come from Russia. So far, the present characteristics of commercially available LGS and LGT crystals, as far as high-performance piezoelectric resonators are concerned, still have to be improved. For $\mathrm{GaPO}_{4}$, there exist to date only one supplier of this crystal.

2. To date no chemical etching for $\mathrm{LGS} / \mathrm{LGT}$ or $\mathrm{GaPO}_{4}$, similar to the Z-cut of quartz has been published.

3. The magnitude of frequency-temperature effects of LGS/ LGT resonators is significantly greater than quartz used in similar vibrating modes; this has been measured for thickness-shear resonators [16].

The strong points of new piezoelectric crystals, to date, are:

1. Thickness-shear LGT resonators and oscillators have been fabricated and tested with performances that are now close to state of the art quartz resonators [17].

2. The frequency-temperature effects of $\mathrm{GaPO}_{4}$ resonators are smaller than their quartz equivalents [11].

3. Several surface wave sensor applications of new crystals at high temperatures have already been demonstrated [18].

4. For beam resonators, recent measurements on thermo-elastic properties of LGS and LGT [19] show that the minimum $Q-$ factor for beam resonators in the frequency range $(10-100 \mathrm{kHz})$ is 4 times higher for LGS and LGT than quartz.

This last point is very important for the development of precision vibrating beam accelerometers and force sensors

\section{Table 5}

Frequency range for resonant frequencies of singly-rotated cuts, $20 \mathrm{~mm}$ long beam resonator vibrating in length-extensional mode.

\begin{tabular}{llll}
\hline Extension & Quartz & $\mathrm{GaPO}_{4}$ & LGS and LGT \\
\hline Freq. (kHz) range & $127-175$ & $97-128$ & $90-140$ \\
\hline
\end{tabular}

where LGS and LGT could bring a significant improvement over quartz.

\section{Conclusion}

In conclusion, temperature-compensated cuts are found theoretically and experimentally for length-extensional modes of singly-rotated cuts of $\mathrm{GaPO}_{4}$, LGS, LGT. The model also predicts the existence of temperature-compensated cuts for flexural modes at high temperatures and temperature-compensated cuts for cylinders in torsional modes.

Possible applications involve miniature sensors at high temperatures, e.g. for the automotive industry. Actual development of those applications is conditioned by the possibility to micromachine miniature beam resonators efficiently. Meanwhile, scaled models can be made by photolithography and precision diamond saw cutting.

\section{References}

[1] W. Wallnöfer, P.W. Krempl, A. Asenbaum, Determination of the elastic and photoelastic constants of quartz-type $\mathrm{GaPO}_{4}$ by Brillouin scattering, Phys. Rev. B 49 (1994) 10075-10080.

[2] S. Sakhara, P. Senushencov, A. Medvedev, Yu. Pisarevsky. "New data on temperature stability and acoustical losses of langasite crystals". IEEE Int. Freq. Control. Symp. 1995, IEEE cat \# 95CH-3575-2, pp. 647-652.

[3] Growing the large lanthanum gallium silicate single crystals by Czochralski method B.A. Dorogovin, S.Yu. Stepanov, A.B. Doubovski, A.A. Tsegleev, G.A. Lapteva, V.Y. Kurochkin, I.M. Philippov, Frequency control symposium and exhibition, 2000, Proc. 2000 IEEE/EIA Int. (2000) 169-173.

[4] E. Momosaki. "A brief review of progress in quartz tuning fork resonators". Proc. IEEE Int. Freq. Cont. Symp., Orlando, Florida, pp. 552-565, June 1997.

[5] F.J. Giessibl, High-speed force sensor for force microscopy and profilometry utilizing a quartz tuning fork, Appl. Phys. Lett. 73 (26) (28 December 1998) 3956.

[6] D.E. Diller, N.V. Frederick, Torsional piezoelectric crystal viscometer for compressed gases and liquids, Int. J. Thermophys. 10 (1) (Jan 1989) 145-157.

[7] L. Delmas, F. Sthal, E. Bigler, B. Dulmet, R. Bourquin, Temperature-compensated cuts for length-extensional and flexural vibrating modes in $\mathrm{GaPO}_{4}$ beam resonators, IEEE Trans. Ultrason. Ferroelectr. Freq. Control 52 (4) (April 2005) 666-671.

[8] P. Truchot and R. Bourquin. "Torsional quartz resonators". In: Proceedings of 8th European Frequency and Time Forum, Munchen, Germany, 9-11 March, pp. 862-871, (1994).

[9] F. Sthal, E. Bigler, R. Bourquin, Thermal compensation in $\mathrm{GaPO}_{4}$ beam resonators: Experimental evidence for length extensional mode, IEEE Trans. Ultrason. Ferroelectr. Freq. Control. 54 (1) (Jan 2007) 196-197. 
[10] R. Bechmann, A.D. Ballato, T.J. Lukaszek, Higher order temperature coefficients of the elastic stiffnesses and compliances of alpha-quartz, Proc. IRE (1962) 1812

[11] W. Wallnöfer, J. Stadler, P. Krempl. "Temperature dependance of elastic constants of $\mathrm{GaPO}_{4}$ and its influence on BAW and SAW devices". Proceedings of 7th European Frequency and Time Forum, Neuchâtel, 16-18 March 1993, pp. 653-657.

[12] D.C. Malocha, E. Adler, S. Frederick, M. Chou, M.P. de Cunha, R.C. Smythe, R. Humbold and Y.S. Zhou, Recent measurement of materials constants versus temperature of langate, langanite and langasite, Proceedings of 54th IEEE Ann. Freq. Cont. Symp., Kansas city, Missouri, 7-9 June, pp. 200-205, (2000).

[13] IEEE Standard on Piezoelectricity 176-1949, Proc. IRE 37 (1949) 1378-1395.

[14] ANSI/IEEE Std 176-1987, IEEE Standard on Piezoelectricity, (1987).

[15] R. Bourquin and B. Dulmet, "New sets of data for the thermal sensitivity of elastic coefficients of langasite and langatate". In: Proceedings of 20th
European Frequency and Time Forum, Braunschweig, Germany, 27-30 March pp. 26-32, (2006).

[16] Smythe, R.C. Helmbold, R.C. Hague, G.E. Snow, K.A., “Langasite, langanite, and langatate resonators: recent results", Proc. IEEE Frequency Control Symposium 1999 Joint EFTF, ISBN: 0-7803-5400-1 vol. 2, pp. 816-820.

[17] Imbaud, J. Galliou, S. Romand, J.P. Abbe, P. Bourquin, R. “ Noise measurements of $10 \mathrm{MHz}$ LGT crystal Oscillators”, Proc. IEEE Frequency Control Symposium 2007 Joint 21st EFTF, ISBN: 978-1-4244-0647-0, pp. 1251-1254.

[18] Thiele, J.A. Pereira da Cunha, M., Dual configuration high temperature hydrogen sensor on LGS SAW devices, Proc. 2004 IEEE Ultrasonics Symp., ISBN: 0-7803-8412-1, Vol. 2, pp. 809-812.

19] Bourquin, R. Sthal, F. Bigler, E., "Limitation of the Q factor due to the thermo elastic damping in flexural Langasite and Langatate resonators", Frequency Control Symposium 2007 Joint 21st EFTF, ISBN: 978-1-4244-0647-0, pp. 685-689. 